\title{
PROBLEMAS FRENTE A LA ACTUACIÓN DE PRUEBAS EN LAS AUDIENCIAS VIRTUALES
}

\section{Problems with the performance of evidence in virtual audiences}

Ruben Gonzales Ormachea*

Universidad Nacional Mayor de San Marcos

\author{
Andrea Ochoa Coripuna** \\ Universidad Nacional Mayor de San Marcos
}

Abogado por la UNMSM. Adjunto de Docencia en la Facultad de Derecho de la PUCP. Estudios de maestría en Derecho Procesal por la PUCP. Miembro del Grupo de Investigación de Derecho Procesal Crítico y Constitución - GIDEPROC. Asociada del área de solución de conflictos de Rodas \& Asociados. ORCID iD: 0000-0002-7145-1090. Contacto: rgonzaleso@pucp.edu.pe

** Abogada por la UNMSM. Adjunta de Docencia en la Facultad de Derecho de la PUCP. Estudios de maestría en Derecho Procesal por la PUCP. Miembro del Grupo de Investigación de Derecho Procesal Crítico y Constitución - GIDEPROC. Asociada del área de solución de conflictos de CMS GRAU Abogados. ORCID iD: 0000-0002-9064-1412. Contacto: andrea.ochoa766@gmail.com 


\section{Resumen:}

En pandemia, las audiencias, en la mayoría de los casos, han sido realizadas de manera virtual. Sin embargo, si bien ha habido buenos resultados, no es óbice preguntarse si éstas pueden llevarse a cabo con la misma efectividad que una presencial. En ese sentido, los autores han considerado analizar la legislación comparada y nacional sobre la audiencia de pruebas. Luego, se identifican los problemas de la audiencia de pruebas virtual; específicamente, el análisis se detiene en la psicología del testimonio y cómo su desarrollo puede ser influenciada por la virtualidad. Finalmente, se sugieren propuestas para la mejora del servicio de nuestra administración de justicia.

\section{Abstract:}

In a pandemic, the hearings, in most cases, have been held virtually. However, although there have been good results, it is not an obstacle to wonder if these can be carried out with the same effectiveness as a face-to-face session. In this sense, we have considered analyzing the comparative and national legislation on the hearing of evidence. Next, we have identified the problems with the virtual test audience; specifically, we have focused on the psychology of testimony and how its development can be influenced by virtuality. Finally, we have suggested proposals to improve the service of our administration of justice.

\section{Palabras claves:}

Audiencia de pruebas - Virtualidad - Psicología del testimonio - Proceso civil - inmediación procesal

\section{Keywords:}

Hearing of evidence - Virtuality - Psychology of testimony - Civil process

- Procedural immediacy

\section{Sumario:}

1. Introducción - 2. Legislación comparada - 3. Legislación nacional - 4 . Propuestas -5 . Conclusiones -6 . Lista de referencias 


\section{INTRODUCCIÓN}

A raíz del estado de emergencia nacional decretado por el gobierno peruano, el pasado 15 de marzo de $2020^{1}$, a consecuencia de la pandemia generada por el SARS-CoV-2, el Poder Judicial empezó a implementar una serie de medidas a fin de evitar que la administración de justicia paralice.

La tecnología ha cobrado una importancia tal que hoy ya no se puede concebir el proceso civil sin la utilización de la plataforma Google Meet. La digitalización ha sido tanto a nivel privado como público. La tecnología, pues, ha sido la protagonista con o sin fallas en la celebración de las audiencias virtuales.

Con la audiencia de pruebas online, no solo ha permitido registrar los hechos de manera sencilla sino también duradera, ya que las grabaciones, anexadas al expediente judicial, pueden ser vistas reiteradas veces, a diferencia de las presenciales, que no son grabadas y solo quedan en la memoria del juez.

Sin lugar a duda, la virtualidad a nivel del proceso judicial ha generado una serie de ventajas tanto para los justiciables, como para los propios jueces. Así, pues, anteriormente veíamos el desplazamiento de las partes y sus abogados a las distintas sedes judiciales a nivel nacional para la asistencia a las audiencias.

Sin embargo, ahora ello se ha visto disminuido gracias a la realización de las mismas a nivel de la plataforma virtual que el Poder Judicial permite. Adicional a ello, las audiencias pueden quedar grabadas de manera más rápida y, de ser el caso se requiriese, podrían ser escuchadas por el juez en un momento posterior.

No obstante, es necesario preguntarse si todas las audiencias pueden llevarse a cabo con la misma efectividad. Por ejemplo, no vemos mayor inconveniente cuando se trata de un informe oral o informe de hechos, en donde los abogados y las partes que lo solicitaron exponen lo conveniente para sus intereses; sin embargo ¿qué sucede con la audiencia de pruebas?

Así, pues, a propósito de la nueva forma de llevar las audiencias en general a nivel judicial, tenemos los casos en los que las partes ofrecen como un medio probatorio la declaración de su contraparte o el testimonio de un testigo, lo que llevaría a convocar una audiencia de pruebas para su actuación².

Decreto Supremo N 044-2020-PCM, publicado el 15 de marzo de 2020 en el diario oficial "El Peruano".

2 Sobre este punto, Kisch (1940, p. 132) establece que el juez debe tener conocimiento de las manifestaciones de las partes y de las pruebas no indirectamente, es decir, por un informe oral o un escrito de tercero; sino, directamente, por audiencia directa de las partes y por percepción inmediata de todo lo que conduzca a probar los hechos. 
A diferencia de lo que sucedía con dichas audiencias a nivel presencial, llevarlas a cabo de manera virtual ciertamente genera complicaciones ${ }^{3}$; más aún para la obtención de información fidedigna, al no encontrarse el juzgador en un mismo espacio que la persona a declarar.

En esa misma línea de ideas, la psicología del testimonio brinda pautas a los juzgadores para que los mismos puedan verificar qué tan confiable puede llegar a ser un determinado testimonio en el marco de un proceso judicial y, lograr así, una decisión con mayor convicción; sin embargo, es necesario preguntarse si el juez a nivel de una audiencia virtual logra una similar o mejor verificación.

Ciertamente, la diferencia de espacios puede llevar a que los referidos testimonios sean inclusive manipulados o que los jueces no puedan tomar en cuenta ciertos rasgos de la personalidad de las personas que declaran y/o testifican.

Es por ello que, este trabajo se encuentra dirigido a analizar cuáles son las complicaciones que, hoy por hoy, se presentan en el marco de la realización de las audiencias virtuales, buscando de esta manera aportar soluciones para la efectivización de las mismas y que no sean óbice para la obtención de decisiones adecuadamente fundamentadas.

\section{LEGISLACIÓN COMPARADA}

Como punto de partida, consideramos que es necesario analizar a nuestros países vecinos ${ }^{4}$, a efectos de evaluar cuál es el panorama que ellos ha tenido

3 Al respecto, Edhin Campos (2021) indicaba que muchos abogados cuestionaron la realización de las referidas audiencias partiendo de una supuesta vulneración al principio de inmediación "es más, muchos han planteados diversos recursos judiciales que han ido desde la solicitud de nulidad de proceso, suspensión del juicio oral hasta que se reestablezca la normalidad y la interposición de procesos constitucionales de hábeas corpus".

4 Por ejemplo, en Costa Rica, Arellano, Cora, García y Sucunza (2020) reportan lo siguiente: "[e]l Protocolo de Manejo de Audiencias Virtuales en los Procesos Laborales y civiles en Costa Rica recibió la aprobación de Corte Plena, en la sesión ordinaria del lunes 4 de mayo. El protocolo contiene disposiciones generales que incluyen el objeto de la realización de la audiencia, el ámbito de aplicación, la autenticación y el uso de tecnologías seguras, la identificación de las partes, el lugar, la vestimenta y el tiempo de las audiencias, así como el tema del manejo de la prueba y el respaldo de las mismas. Otros elementos como los deberes éticos, la publicidad, el uso de intérpretes, la accesibilidad, la dirección de la audiencia, la recepción de declaraciones, las formas alternativas de resolución de conflictos, los sistemas a utilizar y lo que se debe hacer ante la interrupción de servicios son parte de las pautas generales. Además, el documento contiene disposiciones específicas que refieren a las actuaciones previas a la audiencia, así como durante su realización" (p. 33). 
frente a las audiencias virtuales $y$, además, tomar como modelo las soluciones que han implementado ${ }^{5}$ a semejantes situaciones.

\subsection{Chile}

Con fecha 2 de abril de 2020, se promulgó y publicó la Ley № 21226, cuyo propósito fue establecer un régimen jurídico especial para las audiencias que pueden verse afectadas por el estado de excepción de catástrofe del COVID-19. En esa línea, el artículo 10 de la citada ley señala lo siguiente:

En los casos en que, conforme a las disposiciones de esta ley, un tribunal disponga proceder en forma remota, deberá tomar todas las medidas necesarias que aseguren las condiciones para el cumplimiento de las garantías judiciales del proceso, contempladas en la Constitución Política de la República y en los tratados internacionales ratificados por Chile y que se encuentren vigentes.

En esa línea, las audiencias se están realizando de modo virtual o electrónico a fin de garantizar el acceso a la justicia y el debido proceso. En ese sentido, a través de la ley, se ha permitido al Poder Judicial chileno utilizar los medios electrónicos correspondientes, resaltando su utilización flexible y oportuna que permite el respeto al derecho de las partes.

\subsection{Colombia}

En el caso de Colombia, sin perjuicio de la oralización de su sistema de justicia, el artículo 372 del Código General del Proceso, vigente a partir de 2016, consagra que "el juez, salvo norma en contrario, convocará a las partes para que concurran personalmente a una audiencia con la prevención de las consecuencias por su inasistencia, y de que en ella se practicarán interrogatorios a las partes (...)".

\footnotetext{
Como consideraciones generales, Arellano, Cora, García y Sucunza (2020) concluyen lo siguiente: "[c]asi la totalidad de países [de Latinoamérica] habilitaron la realización de audiencias virtuales, circunstancia que puede aparecer como una decisión trascendental pero problemática dado que: (i) la mayoría de los Poderes Judiciales no contaban con plataformas propias; (ii) las capacitaciones en su uso de operadores internos o externos no se ha generalizado (menos para la toma de una audiencia); (iii) en general, no se crearon protocolos para la toma de audiencias que contengan, más allá de las funcionalidades de la herramienta, reglas sobre cómo compatibilizar el medio al fin. Es decir, cómo la toma de la audiencia a través de ese medio tecnológico, facilita y garantiza los derechos y garantías constitucionales-convencionales. No sólo en un plano dogmático o teórico, sino operativo y pragmático" (p. 87).
} 
El texto del artículo 372 del Código General del Proceso colombiano es similar en algunos términos del artículo 203 de nuestro CPC, requiriéndose para su realización lo siguiente: i) la presencia de los sujetos procesales en la audiencia de manera permanente; ii) el predominio de la palabra hablada para la comunicación entre los sujetos del proceso; iii) la inmediación y concentración para que el juez permanezca en las audiencias y realice el mayor número de actuaciones en el menor tiempo posible.

\subsection{Uruguay}

En el caso de Uruguay, el Código General del Proceso adoptó el Código Procesal Civil Modelo para Iberoamérica. Así, sin perjuicio de la virtualidad de las audiencias, el artículo 340 del Código consagra que "las partes deberán comparecer a la audiencia en forma personal, salvo motivo fundado, a juicio del tribunal, que justificare la comparecencia por representante (...)".

Para Santiago Pereyra (2011), el texto del artículo 340 del Código General del Proceso uruguayo consagra soluciones modernas y eficaces en pos de la inmediación:

a) Sienta como regla general que las personas físicas capaces deben comparecer a la audiencia preliminar en forma personal y no por representante, salvo motivo fundado debidamente justificado. La comparecencia personal es esencial para asegurar el contacto directo del juez con las partes sustanciales, verdaderos interesados en la cuestión litigiosa $(\ldots)^{6}$ (p. 278).

\section{LEGISLACIÓN NACIONAL}

Con la publicación del Código Procesal Civil (en adelante, CPC) en el año 1993 se buscó hacer énfasis en el principio de la inmediación ${ }^{7}$. Tan es así que,

6 El profesor uruguayo Santiago Pereyra (2011) comenta que "la Suprema Corte de Justicia uruguaya ha recogido en forma expresa estos conceptos al decir que la norma impone 'a ambas partes litigantes la carga de comparecer en forma personal a la audiencia preliminar' y que ello 'responde a uno de los principios que sustentan la nueva legislación procesal, asegurando la presencia en la audiencia del Juez y de las partes en el conflicto sometido a su decisión' (Sentencia 87/93- Cf. Sentencia del TAC 70 No. 16/99)" (p. 278).

7 Con más precisión, el maestro Devis Echandía (1997) nos explica que la inmediación procesal es la inmediata comunicación entre el juez y las partes, la constatación de los hechos alegados y la actuación de los medios de prueba. Por eso, a su criterio, la inmediación puede ser subjetiva y objetiva. Así, "se entiende por inmediación subjetiva la proximidad o contacto entre el juez y determinados elementos personales o subjetivos, bien sean los sujetos mismos del proceso, o personas distintas de tales sujetos, es decir, terceros. La manifestación principal del requisito 
el artículo 202 indica expresamente que la audiencia de pruebas se dirigirá personalmente por el juez, esto es, éste tendría la información de primera mano relacionada a los medios probatorios que requieran actuación ${ }^{8}$. Cabe precisar que el actual CPC regula el proceso por audiencia9.

Respecto a la inmediación, Taipe (2016, p. 339) detalla que "este principio busca mantener la más íntima relación posible, el más estrecho contacto entre el juzgador de una parte y los litigantes y la totalidad de los medios probatorios de la otra".

En el diseño del CPC, se concebía originalmente que:

[E]l juez, las partes y quienes tengan que informarle al primero sobre lo ocurrido en aquella parte de la realidad que es materia del conflicto - como los testigos, por ejemplo- deben estar en contacto directo. Solo así el juez estará capacitado para, luego de conocer por versión de sus protagonistas el drama humano que guarda el conflicto, resolver en y con justicia (Monroy, 2003, citado en Ariano, 2007, p. 21).

Esta importante función del juez se ve reflejada también en el artículo ॥ del Título Preliminar en conjunto con el artículo 50.1 del CPC, en los cuales se

de inmediación subjetiva es la que impone que el acto de prueba se practique en presencia de su destinatario, es decir que la prueba se practique ante el juez que debe apreciar su mérito. La inmediación objetiva se refiere a la comunicación del juez con las cosas y los hechos que interesan al proceso" (p. 68).

8 Con más precisión, el maestro Devis Echandía (1997) nos explica que la inmediación procesal es la inmediata comunicación entre el juez y las partes, la constatación de los hechos alegados y la actuación de los medios de prueba. Por eso, a su criterio, la inmediación puede ser subjetiva y objetiva. Así, "se entiende por inmediación subjetiva la proximidad o contacto entre el juez y determinados elementos personales o subjetivos, bien sean los sujetos mismos del proceso, o personas distintas de tales sujetos, es decir, terceros. La manifestación principal del requisito de inmediación subjetiva es la que impone que el acto de prueba se practique en presencia de su destinatario, es decir que la prueba se practique ante el juez que debe apreciar su mérito. La inmediación objetiva se refiere a la comunicación del juez con las cosas y los hechos que interesan al proceso" (p. 68).

9 En el proceso por audiencia de nuestro CPC, la escritura y la oralidad conviven, ya que ambas son dos medios de comunicación posibles en el proceso civil. Si bien nuestro proceso civil por audiencias siempre ha sido "mixto", no vale descuidar otros aspectos que influyen las condiciones sobre cómo se desarrolla el proceso. Así, a palabras del profesor español Perfecto Andrés Ibáñez, lo que garantiza el debate público y oral en las audiencias procesales es "el carácter inmediato, es decir, no mediado o libre de interferencias, de la relación de todos los sujetos procesales entre ellos y con el objeto de la causa, que propicia tal modo de concebir el enjuiciamiento" (citado en Meroi, 2009). 
regula el principio de dirección del proceso ${ }^{10}$ o principio de autoridad. Es así como, el juez no podrá delegar importante función como director al interior del proceso judicial, con mayor énfasis en lo relacionado con la audiencia de pruebas.

Antes del estado de emergencia nacional por el COVID-19, decretado por el gobierno peruano, el juez iniciaba, dirigía y terminaba la audiencia de pruebas que usualmente se realizaba en su despacho. Sin embargo, en estos tiempos de pandemia, los jueces han venido utilizando la tecnología para la realización de las audiencias virtuales.

En consecuencia, la realización de audiencias virtuales es compatible con la legislación procesal vigente porque sencillamente no hay norma que prohíba la posibilidad de llevar a cabo audiencias virtuales. Así, si bien el artículo 202 del CPC establece que el juez dirige la audiencia de manera presencial, no significa que no pueda hacerlo a través de un computador ${ }^{11}$.

Más adelante explicaremos los problemas generados de las audiencias virtuales. Sin embargo, es importante resaltar que las audiencias de prisión preventivas por videoconferencia en materia penal -algunas televisadas por Justicia TV - han dado señales que sí es viable realizar litigios difíciles a través de la tecnología; así, la capacitación del juez y auxiliar jurisdiccional es indispensable.

10 Sobre el asunto, el jurista italiano Franco Cipriani (2003) comenta que "el juez (...) administra y conduce el proceso desde el inicio hasta el final ( ) cuenta con amplios poderes discrecionales, con la obvia consecuencia de que no es más, como los ordenamientos liberales 'una marioneta que puede moverse solo si las partes le tiran de los hilos', sino el 'directo', el 'timonel', el representante profesional del bien común" (p. 62).

11 Al respecto, Renzo Cavani y Alessandro Vergel (2020) opinan que podría pensarse que la norma que obliga a que la audiencia se realice en el local del juzgado es un obstáculo infranqueable (art. 203, que la limita a la audiencia de pruebas), pero aquí surgen tres alternativas:

a. Que el juez efectivamente asista al local del juzgado y que realice la videoconferencia desde allí.

b. Que el juez consulte a las partes si es que están de acuerdo con la realización de una audiencia virtual, cada uno desde sus hogares, incluyéndole a él mismo.

c. Interpretar extensivamente el primer párrafo del art. 205 - que permite la realización de la audiencia fuera del local del juzgado - entendiendo que la no comparecencia de los intervinientes y de las partes por causa del aislamiento social, e incluso por economía procesal, obedece a un "motivo atendible" a criterio del juez. Aquí, por tanto, la realización de la audiencia no sería propiamente en el domicilio de un específico sujeto procesal sino, dado que es una videoconferencia, irigurosamente no sería en el domicilio de ninguno de ellos!. 


\subsection{Primer otrosí: la psicología del testimonio en el Perú}

La psicología se ha encontrado ligada desde mucho tiempo atrás al tema judicial y, en específico, la psicología del testimonio busca brindar pautas para las declaraciones a nivel penal, a efectos de intentar determinar la exactitud y confiabilidad de los testimonios.

No obstante, esta importancia trasciende también a nivel de los juicios civiles, toda vez que es necesario que la misma también sea utilizada para la interpretación a nivel de las audiencias, en específico, la audiencia de pruebas.

Con relación al testimonio ${ }^{12}$, la norma regula este medio probatorio típico en el artículo 222 del CPC, indicando como regla que toda persona capaz tiene el deber de declarar como testigo, si no tuviera excusa o no estuviera prohibido de hacerlo en la audiencia, de acuerdo a las causales establecidas en el propio código.

Sobre el particular, la doctrina ha visibilizado que es importante tener en cuenta que existen aspectos psicológicos a nivel de los testimonios de las

12 Sobre el tema, Alejandro Abal Oliú (2014) explica que antiguamente (la prueba testimonial) era la prueba por excelencia: el escaso conocimiento de la escritura hacía que casi todas las pruebas fueran de carácter testimonial, y los instrumentos públicos y privados que hoy tienen un gran valor en el conjunto de los medios probatorios, prácticamente no tenían importancia. Pero a partir de los siglos XVI y XVII se inició una especie de reacción contra la prueba testimonial. Se inició un proceso por el cual los autores de Derecho y también la Jurisprudencia, cada vez desconfiaban más de la prueba testimonial, llegándose, el tiempo de la codificación, al máximo de desprestigio de este tipo de prueba. Tal reacción contra la prueba testimonial es paralela a un prestigio creciente de la prueba instrumental, la que empieza a asentarse y extenderse cada vez más en el mundo occidental. La reacción contra la prueba testimonial arranca de una experiencia extraída de los hechos: en la realidad la prueba testimonial conduce a resultados poco satisfactorios porque, como decía Mattirolo, para que la prueba testimonial tenga validez desde el punto, digamos científico, o aún desde el punto de vista de los hechos, se requiere que se cumpla una doble exigencia: 1) que el testigo no se engañe, y 2) que el testigo no quiera engañar. (...) No obstante, en los últimos tiempos, a fines del siglo pasado y en lo que va del presente, la prueba testimonial ha tenido una especie de rehabilitación en virtud de lo que ha pasado a ocupar el puesto que había perdido en el conjunto de los medios probatorios. Esto se debe en buena parte a que el adelanto operado en el campo de la psicología y de los medios científicos para controlar la veracidad de los testigos, brinda la posibilidad de extraer de ellos declaraciones aproximadamente exactas aun pasando por encima de aquellas dos reflexiones que formulaba Mattirolo. Se puede saber con relativa exactitud cuáles son los casos en los cuales el testigo se engaña aún sin quererlo, y cuáles son los casos en los cuales el testigo deliberadamente quiere engañar. Quiere decir que merced al progreso de la psicología existe hoy una especie de contralor del testimonio que permite depurarlo en buena parte de las desviaciones en que espontánea o premeditadamente incurren los testigos y que antes le quitaban todo valor práctico en los hechos (Peirano Facio, 1968, citado en Abal, 2014, pp. 14-15). 
personas que deben ser tomados en consideración por el juez como director del proceso, en el marco de la celebración de la audiencia de pruebas. En ese sentido, Alejandro Solís (2000, p. 1018) los dividió en aspectos relacionados a su personalidad, salud mental y/o moralidad:

\section{i) Sobre la personalidad:}

Existen aspectos de la personalidad que pueden llegar a generar variantes en los testimonios de los testigos. Uno de ellos, la edad del testigo, dado que, poniéndonos en el supuesto de los menores de edad, los testimonios que brindan podrían tener cierto grado de subjetividad.

Este pensamiento no es ajeno a la norma. Así, pues, el artículo 229 inciso 1 del CPC ya indica como regla que el absolutamente incapaz no podrá prestar testimonio. Remitiéndonos al artículo 43 inciso 1 del Código Civil, los menores de dieciséis años son los absolutamente incapaces.

Ahora bien, este artículo tiene una excepción en lo establecido por el último párrafo del 194 del CPC, en donde se verifica que el juez podría llamar a comparecer a una audiencia de pruebas a un menor de edad con discernimiento.

Esto es, sí sería posible que un menor dieciséis años con discernimiento, participe en la audiencia testificando, cuando así lo considerase el juez, quien tendría la importante labor de poder verificar la confiabilidad del testimonio que se está brindando.

Situación parecida sucede con los adultos mayores, quienes son personas que infunden respeto y, además, en muchas culturas sus declaraciones podrían ser tomadas a ojos cerrados como ciertas; no obstante, lo cierto es que, podrían también ser imprecisas. Es por esa razón que, frente a estos casos el juez no debería dejarse llegar por subjetividades, sino más bien analizar si el adulto mayor que se encuentra testificando brinda información oportuna y fidedigna.

Otro rasgo a tomarse en consideración sería el grado de instrucción de la persona que testifica, dado que un testigo que cuente con ciertos conocimientos en determinadas materias, en la mayoría de los casos podría brindar mayor detalle frente a testigos que no tengan esa información o que sean analfabetos. Ciertamente, ello no se debería generalizarse de un primer momento; no obstante, podría ser una pauta que tomar en consideración.

\section{ii) Sobre la salud mental:}

En estos casos, Solís incluye a las personas que puedan tener trastornos psicóticos u otras enfermedades psiquiatrías que las lleven a tener alteraciones 
de la realidad y que compliquen brindar un testimonio sin que el mismo pueda carecer de confiabilidad. De la misma manera, se incluiría a las personas con retraso mental por la misma imposibilidad antes explicada.

Al respecto, el CPC descarta a priori los testimonios de los absolutamente incapaces, que, en este caso, quedarían fuera como testigos las personas antes indicadas; sin embargo, a nivel penal los mismos sí se admiten.

Así, pues, en el artículo 142 del Código de Procedimientos Penales indica que los menores de dieciocho años y personas a quienes por falta de desarrollo o decadencia mental se les considere en un estado intelectual inferior a lo normal, podrán declarar como testigo sin necesidad de juramente o promesa.

Vemos entonces que, no se descarta de primera mano los testimonios de las personas antes indicadas, sino que - se flexibiliza - su declaración, toda vez que los juramentos o promesas se encuentran relacionados a buscar comprometer a quienes los realizan; sin embargo, luego de ello, el propio artículo indica que el juez se encuentra en la obligación de informar que, si se falta a la verdad, se incurrirá en responsabilidad penal.

Consideramos que descartar a priori la declaración de las personas que tienen comprometida su salud mental como se hace a nivel del CPC no es del todo acertada. Desde luego, hay ciertos grados en estas enfermedades que bien podrían ser analizados por el propio juzgador para determinar cuándo sí podría proceder el testimonio.

Es más, la parte que ofrece el testimonio podría inclusive ofrecer un peritaje psicológico que respalde la ecuanimidad del testigo o, de ser el caso lo considerase, el propio juez podría nombrar un perito para que se encargue de hacer ello con mayor imparcialidad.

\section{iii) Sobre la moralidad:}

Actualmente, nuestro CPC no excluye las declaraciones de personas que pudiesen tener una cuestionable moralidad, como sí lo hizo anteriormente el Código de Procedimientos Civiles de 1912 que vetaba para testificar a las personas indignas de fe por razón de malas costumbres notorias o de vagancia.

Lo más cercano a este punto podría ser el inciso 2 del artículo 229, en donde se indica que están prohibidos a declarar aquellos que han sido condenados por algún delito que, a criterio del juez, afecte su idoneidad. Podríamos encajar aquí a los condenados por querella, injuria o calumnia, cuyo testimonio ha sido ofrecido por alguna de las partes; sin embargo, es preciso cuestionar cómo se realizaría este filtro de verificación de la condena. Juega un papel importante en 
este punto el abogado de la contraparte, quien podría poner en conocimiento la sentencia condenatoria a efectos de que se rechace dicho testimonio.

Por otra parte, en el caso que las personas a testificar sean conocidas públicamente y que puedan tener una credibilidad cuestionable, podría generarse ciertos sesgos a priori en el juzgador para tomar en cuenta lo que se pudiese detallar en sus testimonios; sin embargo, debemos hacer énfasis en que la norma no hace diferencia por estas declaraciones, por lo que diferenciarlas ingresaría en la subjetividad ${ }^{13}$.

Como podemos apreciar, existen diferentes aspectos a evaluar por parte del juzgador con relación a los testimonios brindados por los testigos ofrecidos como medios probatorios. Ahora bien, las mismas limitaciones podrían ser extendidas a las declaraciones de partes que se solicitasen, siendo nuevamente necesario que el juez cumpla un papel importante para verificar que tan fidedigna es la información que se obtiene.

Frente a este panorama, es necesario preguntarnos si todo este análisis podría ser realizado a nivel de las audiencias virtuales que tenemos hoy por hoy, como parte de las medidas que buscan evitar los contagios por la pandemia. ¿Acaso el juez podría hacer la verificación sobre si el testigo no tiene cierto grado de afectación a su salud mental que no se haya percibido? O, ¿̇i el testigo mayor de edad no logra concatenar las ideas que brinda por tener un grado de demencia senil?, o ¿podría verificar si el menor de dieciséis años cuyo testimonio se ofreció sí podría estar dando un testimonio fidedigno o se encuentra leyendo ciertos apuntes brindados previo a la audiencia?

Si bien, en cuanto a la operatividad de las audiencias, el artículo 204 CPC obliga a que la audiencia de pruebas sea registrada en video o audio e incorporada al expediente judicial, sostenemos que no puede ser suficiente para la convicción judicial sobre la credibilidad del testimonio.

En efecto, las reiteradas revisiones del video de la audiencia de pruebas, incorporado en el expediente, no garantizan que el testimonio sea cada vez

13 Con a la confiabilidad del testimonio, la profesora Ledesma Narváez (2016) indicó que algunas legislaciones permiten superar la prohibición de la prueba al no reunir la edad mínima requerida, mediante una suerte de conversión de la testimonial en prueba indiciaria. Sobre el particular, señala Kielmanovich $(2001$, p. 223) que las prohibiciones establecidas por ley no pueden dejarse de lado mediante la transformación de una prueba en otra, por más desactualizadas que se encuentren las razones que condujeron a su establecimiento, cuestión que en todo caso no habilitaría a corregirlas mediante la realización de actos reñidos con el orden jurídico, haciendo derivar así de ella efectos probatorios a favor de quien ofreció la prueba ilegalmente ordenada (p. 438). 
más fidedigno para la decisión judicial ni implican la realización de la inmediación, puesto que, aparte de la aptitud del testigo (artículo 222 del CPC) y las prohibiciones para serlo (artículo 229 del CPC), el juez no sólo promueve la confrontación entre el testigo y las partes (artículo 209 del CPC), sino también puede interrogar al testigo (inciso 2, artículo 208).

Ahora bien, si el juez considera que la audiencia debe ser realizada de forma presencial, puede citar a las partes y/o testigos. Lo cierto es que la decisión de hacerlo virtual corresponde al juez, quien no solo debe motivar su resolución, sino también conocer la influencia de la tecnología en una declaración de parte o testimonial.

Ciertamente, consideramos que las herramientas de la psicología que pudiese tener el juez para la realización de las audiencias físicas podrían encontrarse comprometidas en el desarrollo de las audiencias virtuales, puesto que -insistiendo- por la aparente falta de inmediación, no habría una inmediación probatoria entre el juez y la prueba actuada.

\subsection{Los problemas suscitados frente a la virtualidad de las audiencias}

Ciertamente, la virtualidad trae una serie de beneficios, principalmente, evitar los contagios por la pandemia; sin embargo, es innegable que, en un año de vigencia de las disposiciones relacionadas a la virtualidad de las audiencias, se hayan podido identificar una serie de vicisitudes a las cuales se enfrenta la administración de justicia.

Así, pues, hemos podido identificar algunos postulados que representan problemas logísticos, metodológicos y legales en el desarrollo de su virtual actuación:

i) Tal y como se indicó previamente, la psicología del testimonio se encuentra presente en el análisis que debe realizar el juez frente a los testimonios o las declaraciones de parte que se le presente, como una herramienta fundamental para tratar de identificar la veracidad ${ }^{14}$ de la información que se le presenta.

14 Cristián Contreras Rojas (2017) nos explica cómo la psicología del testimonio nos ayuda entender la manifestación del declarante, señalando que el acto de mentir tiene como correlato la generación de una mayor carga cognitiva para el sujeto, lo que puede quedar de manifiesto en la conducta del declarante o en el contenido de sus dichos (dependiendo de la corriente que se siga al efecto). En este sentido, se apunta que la persona que intencionadamente relata una historia que se aparta del recuerdo que tiene de los acontecimientos - sea que se trate de una versión totalmente inventada porque no ha presenciado los hechos, sea porque agrega, omite o 
ii) A ella se le suman los principios de inmediación y de dirección del proceso, buscando así una proximidad entre el juez y las partes en una determinada audiencia, lo cual jugaría un rol importante.

iii) Efectivamente, con dicho contacto directo, el Juez podría encontrarse con testigos que, aparentemente, se encuentren en las condiciones necesarias para brindar un testimonio acorde a lo determinado por las normas de la materia (no se cuestionó el ofrecimiento); sin embargo, al verificar su accionar durante el desarrollo de la audiencia, se concluiría lo contrario.

iv) Podríamos colocarnos en el supuesto de personas que, en la medida de que la enfermedad mental que tuviesen no se evidencie en un primer momento, impediría que el mismo sea cuestionado como medio probatorio por la contraparte basándose en este desconocimiento ${ }^{15}$. Sin embargo, al escucharlo u observar sus conductas durante la audiencia presencial, el juez podría caer en cuenta que no es una persona que pueda testificar o que, previo a que se realice ello, sería necesario que pasase por un peritaje psicológico.

v) Sin llevarlo a dicho supuesto, las audiencias físicas también permiten que el juez pueda analizar los gestos y conductas de las personas que, si bien no se encuentren en el caso del párrafo anterior, evidencien un intento de manipulación de la información que se pretende brindar.

vi) Poniendo un ejemplo, en el caso de los testigos que se encuentran ofreciendo sus testimonios para un proceso de prescripción adquisitiva de dominio y se les empiece a consultar acerca de si el demandante ha cumplido con la posesión pacifica, continua y pública durante los diez años, se verifique ciertos titubeos o inexactitud al momento de reconfirmar la cantidad de años.

altera aspectos de lo sucedido- no solo tiene la urgencia por ajustarse al guion que ha fabricado y estudiado, sino que al mismo tiempo, para tener éxito en su embuste, debe poner atención en que el relato modificado calce con lo que los receptores de la mentira saben o pueden averiguar acerca de los mismos sucesos (pp. 294-295).

15 El artículo 303 del CPC indica que la tacha de los testigos únicamente se realizará por causales previstas en los artículos 305 y 307, las cuales hacen referencia a los supuestos de recusación e impedimento de los jueces; sin embargo, en ningún extremo de las mismas se hace referencia a los aspectos psicológicos, por lo que la tacha no sería la herramienta para este cuestionamiento, sino que el justiciable tendría que alegar su pedido en alguna de las causales de prohibición de los testigos regulado en el artículo 229 del CPC. Asimismo, a este cuestionamiento no se le aplicaría el plazo de la tacha. 
vii) Otro ejemplo, en el caso de declaración del menor de edad para un proceso de tenencia y se le empiece a preguntar acerca de lo que piensa respecto al trato que recibe de la madre o padre, se verifique ciertos titubeos o inexactitud al momento de responder. Esto es relevante porque usualmente el menor de edad responde al lado de su progenitor(a); por tanto, puede haber gestos o muecas hacia el menor que pasen desapercibidos por el juez.

viii) Adicional a ello, los testigos podrían leer párrafos prestablecidos en su participación en la audiencia virtual, sin que en muchos casos los jueces puedan constatar e identificar ello. Incluso, sin necesidad de párrafos, pueden leer textos que son proyectos de respuestas a través de la laptop o celular sin que el juez se percate.

ix) Fuera de lo ya comentado con relación a la parte psicológica, a pesar de que se realice un protocolo de identificación de las personas que se presenten a la audiencia (principalmente mostrar el documento de identidad) lo cierto es que, no se puede llegar a determinar con exactitud si la persona que se encuentra participando es la que corresponde. Por tanto, pueden generarse casos de suplantación de identidad y, a pesar de la verificación previa, ello no podría ser finalmente detectado.

\section{PROPUESTAS}

A raíz de la problemática planteada, sugerimos una serie de propuestas en búsqueda de la mejora del servicio de administración de justicia. Así, respecto a la audiencia de pruebas, ofrecemos las siguientes ideas:

i) Podría llevarse a cabo la audiencia de pruebas de manera virtual, tal y como lo establece el protocolo del Poder Judicial; no obstante, de ser el caso que el juez o la contraparte adviertan una situación que amerite sospecha fundada sobre la veracidad del testimonio que se está brindando, el juez se encontraría facultado a suspender la audiencia de pruebas, con cargo a que, junto con las partes, se ponga de acuerdo en una futura fecha para la continuación, pero esta vez, se realizará excepcionalmente de manera física.

ii) Previa a la celebración de dicha audiencia, el especialista encargado deberá cerciorarse de que las cédulas de notificación se encuentren debidamente cursadas, en casos haya participantes que no hayan asistido, mientras que 
los demás estarían válidamente notificados con dicha decisión en la primera audiencia virtual.

iii) La audiencia física será excepcional y podría ser fijada por única vez, razón por la cual el juez deberá emplear todos sus esfuerzos para que los actos procesales se realicen en ella. Si bien la carga procesal de los despachos es bastante alta, a efectos de brindar mejoras, podría buscarse que estas audiencias se realicen en estos términos. En esta audiencia física, el juez podrá evaluar con mayor precisión los testimonios que se brindan y las partes podrían también hacer las preguntas que requiriesen a fin de una correcta valoración del testimonio ${ }^{16}$.

iv) Respecto al riesgo de suplantaciones, consideramos que la Ley de Firmas y Certificados Digitales puede ayudar a la corroboración de identidad de las personas que se apersonan a la audiencia virtual. Así, las partes que se apersonen a la audiencia podrán suscribir digitalmente el acta virtual.

\section{CONCLUSIONES}

A grandes rasgos, consideramos que la virtualidad a nivel judicial claramente ha generado una serie de ventajas que son innegables; sin embargo, es necesario que el Poder Judicial tenga en su radar también las complicaciones que puedan generarse. Por eso, en la línea de buscar mejoras en el servicio de administración de justicia, llegar a las decisiones veraces se hace una consigna.

16 Cristián Contreras (2017) nos explica sobre la valoración probatorio del juez y la psicología del testimonio a partir de los criterios generales, el legislador debe avanzar hacia el señalamiento de ciertos criterios generales que, sin ser taxativos ni vinculantes, sirvan para facilitar la tarea del juez tanto en lo que respecta al análisis teórico de la honestidad y exactitud de las declaraciones como para la subsecuente plasmación de su mérito en el texto de la sentencia. En este sentido, partiendo de la prevención de que no existe ningún indicador absoluto de mendacidad ni de certeza total de lo expresado en un relato fáctico, es menester considerar que los estudios científicos sobre el particular han determinado que la valoración de las deposiciones solo podrá calificarse de objetiva y racional cuando se sustente, al menos, en el análisis de su nivel de contextualización, concordancia interna, coherencia externa, calidad del recuerdo y de ciertas condiciones personales del deponente que coadyuvan en la interpretación correcta de sus dichos. De esta forma, el legislador procesal civil podría indicar que el juez deberá valorar las declaraciones testimoniales atendiendo al grado de veracidad y exactitud de los relatos, para ello tendrá en cuenta su contextualización, concordancia, relación con otras pruebas del proceso, calidad de la memoria del declarante respecto de los hechos que relata o cualquier otra circunstancia que en consideración del juez pueda ser empleada para determinar racionalmente el mérito de este medio de prueba (pp. 303-304). 
Hemos desarrollado los problemas frente a la actuación de las pruebas en las audiencias virtuales. Específicamente, no solo hemos analizado la problemática de las declaraciones testimoniales en las audiencias virtuales, sino también hemos brindado propuestas que ayudan entender el real problema de las declaraciones.

Finalmente, con las palabras de Cristián Contreras (2017), "el desarrollo de los conocimientos en psicología del testimonio en las últimas décadas exige o demanda completar el ejercicio judicial que se desarrolla respecto del contenido del material fáctico que los testigos proveen al proceso" (p. 307).

\section{LISTA DE REFERENCIAS}

Abal, A. (2014). Interrogatorio de testigo en el derecho procesal de Uruguay. Revista de la Facultad de Derecho, (37), 13-52. https://revista.fder.edu.uy/index. $\mathrm{php} / \mathrm{rfd} /$ article/view/318

Arellano, J., Cora, L., García, C. y Sucuza, M. (2020). Estado de la justicia en América Latina bajo el COVID-19: medidas generales adoptadas y eso de TICS en procesos judiciales. CEJA. http://scm.oas.org/pdfs/2020/CP42372TCEJACOVID19.pdf

Ariano, E. (2007, julio). La presencia personal de las partes en la audiencia de pruebas entre el paternalismo y la sanción. Actualidad Jurídica, 164, 21-26.

Campos, E. (2021, 09 de abril). "¿Existen más problemas que bondades en las audiencias judiciales virtuales después de semana santa?". LPDerecho. https://Ipderecho.pe/problemas-bondades-audiencias-judiciales-virtuales-semana-santa-edhin-campos/

Cavani, R. y Vergel, A. (2020, 12 de abril). "¿Audiencias judiciales virtuales?", La Ley. https://laley.pe/art/9543/audiencias-judiciales-virtuales.

Cipriani, F. (2003). Las batallas por la justicia civil. Cultural Cuzco.

Contreras, C. (2017). La valoración de la prueba testimonial en el proyecto de Código Procesal Civil. Una tarea inconclusa. Revista de Derecho (Valdivia), XXX (1), 287-310. https://scielo.conicyt.cl/pdf/revider/v30n1/art12.pdf.

Devis, H. (1997). Teoría General del Proceso, 3a edición. Editorial Universidad

Kisch, W. (1940). Elementos del derecho procesal civil [traducción del profesor Pietro de Castro] R.D. Privado.

Ledesma, M. (2016). Comentario al artículo $229^{\circ}$ del Código Procesal Civil. En Código Procesal Civil comentado por los mejores especialistas, Tomo II (pp. 436-438). Gaceta Jurídica. 
Manzanero, A. (2008). Psicología del testimonio. Una aplicación de los estudios sobre la memoria. Psicología Pirámide.

Mazzoni, G. (2019). La psicología del testimonio. Editorial Trotta.

Pereira, S. (2011). Mecanismos legales para garantizar la efectiva aplicación del principio de inmediación en el proceso por audiencias. En S. Pereira Campos (coord.), Modernización de la justicia civil (pp. 265-294). Universidad de Montevideo.

Stillman, C. (1917). Study in the psychology of testimony. Journal of Criminal Law and Criminology, 8(2), 222-232. https://scholarlycommons.law.northwestern.edu/jclc/vol8/iss2/7/

Taipe, S. (2016). Comentario al artículo $202^{\circ}$ del Código Procesal Civil. En Código Procesal Civil comentado por los mejores especialistas, Tomo II (pp. 335339). Gaceta Jurídica.

Solís, A. (2000). Psicología del testigo y testimonio. Derecho PUCP, (53), 1013-1052. https://doi.org/10.18800/derechopucp.200001.032 